\title{
Preparation and Characterization of Raw and Chemically Modified Sponge-Gourd Fiber Reinforced Polylactic Acid Biocomposites
}

\author{
Taimur-Al-Mobarak ${ }^{1 *}$, Md. Abdul Gafur ${ }^{2}$, Md. Forhad Mina ${ }^{1}$ \\ ${ }^{1}$ Department of Physics, Bangladesh University of Engineering \& Technology (BUET), Dhaka, Bangladesh \\ ${ }^{2}$ Pilot Plant \& Process Development Center, Bangladesh Council of Scientific \& Industrial Research (BCSIR), Dhaka, Bangladesh \\ Email: *taimur_physics@yahoo.com
}

How to cite this paper: Al-Mobarak, T., Gafur, Md.A. and Mina, Md.F. (2018) Preparation and Characterization of Raw and Chemically Modified Sponge-Gourd Fiber Reinforced Polylactic Acid Biocomposites. Materials Sciences and Applications, 9 , 281-304.

https://doi.org/10.4236/msa.2018.92019

Received: December 25, 2017

Accepted: February 11, 2018

Published: February 14, 2018

Copyright $\odot 2018$ by authors and Scientific Research Publishing Inc. This work is licensed under the Creative Commons Attribution International License (CC BY 4.0).

http://creativecommons.org/licenses/by/4.0/ Open Access

\begin{abstract}
This research work has been undertaken to fabricate environmentally friendly biocomposites for biomedical and household applications. Sponge-gourd fibers (SGF) obtained from Luffa cylindrica plant were chemically treated separately using 5 and $10 \mathrm{wt} \% \mathrm{NaOH}$, acetic anhydride and benzoyl chloride solutions. SGF reinforced polylactic acid (PLA) biocomposites were fabricated using melt compounding technique. Surface morphological, structural, mechanical and thermal properties, as well as antibacterial activities of raw and chemically modified SGF reinforced PLA (SGF-PLA) composites were characterized by field emission scanning electron microscopy, Fourier transform infrared spectrometry, X-ray diffractometry, universal testing method, thermogravimetry, and Kirby-Bauer agar diffusion method, respectively. Surface morphology indicates that after treatment of fibers, the interfacial adhesion between PLA and fibers is improved. X-ray diffractometry result shows that chemical treatment of fibers improves the crystallinity and exhibits new chemical bond formation in the composites. After chemical treatment, compressive strength of the composites is found to increase by $10 \%-35 \%$. The thermal stability of the treated fiber reinforced composites is also found to increase significantly. The composites have no antibacterial activities and no cytotoxic effect on non-cancer cell line. Soil burial test has confirmed that the composites are biodegradable. Benzoyl chloride treatment of fibers shows superior mechanical properties and enhances thermal stability among the composites.
\end{abstract}

\section{Keywords}

Sponge-Gourd Fiber, Polylactic Acid, Chemical Modification, Biocomposites, Antibacterial Activities 


\section{Introduction}

Material researchers, engineers and scientists are always determined to produce either improved traditional materials or completely novel materials; composites are an example of the second category. In recent years, the development of biocomposites from biodegradable polymers and natural fibers have attracted great interests in the composite science, because they could allow complete degradation in soil or by composting process and do not emit any toxic or noxious components [1]-[6].

Among biodegradable plastics, polylactic acid (PLA), a linear aliphatic thermoplastic, has been one of the most promising candidates for various applications, because of its agricultural origin and biodegradability [7]. High-molecular weight PLA is generally prepared by the ring-opening polymerization of lactide which in turn is obtained from the fermentation of corn, sugar beet etc. [8] [9]. Pure PLA can degrade to carbon dioxide, water, and methane in the environment over a period of several months to two years, compared to other petroleum plastics needing very longer periods [10] [11]. On the other hand, it is well known that the fiber reinforcement is a viable method to improve the material properties of biodegradable polymers and to reduce the overall costs of the prepared materials [12]. Sponge-gourd fiber (SGF) is such a natural fiber extracted from the sponge-gourd plants and is extensively grown in Bangladesh. Recently, uses of SGF as reinforcing material in fabrication of polymer-SGF composites have raised great interest and expectations among materials scientists and engineers [13]-[21].

The primary advantages of using this fiber as additive in polymer are that it has low cost, low density, non-abrasive nature, high possibility of filling levels, low energy consumption, high specific properties, biodegradability, wide varieties, availability throughout the world and a generation of rural/agriculture based economy. The main components of SGF are cellulose and lignin of which the amount of the former one varies from 55\% - 90\% and the second one is within the range of $10 \%-23 \%$ [19]. Despite its great advantages and scopes, SGF has a drawback that precludes its promising uses in composites fabrication. The disadvantage is that SGF is hydrophilic in nature and its average moisture content is $11 \mathrm{wt} \%$ [19], which reduces its durability. Therefore, it is necessary to modify the fiber surface without genetic manipulation in order to alleviate hydrophilicity of the fiber so that its adhesion with the hydrophobic moiety of polymers can be improved. Effect of chemical modifications on surface morphological, structural, mechanical, and thermal properties of sponge-gourd natural fiber were investigated [22], where it is reported that the mechanical properties and thermal stability of the chemically modified fibers are found to increase. Without surface modification of SGF, a few research works have been studied before [20] [21]. In these investigations, the reported mechanical properties such as tensile strength, flexural strength, Young's modulus, and tangent modulus of untreated SGF reinforced composites were less than those obtained by treated 
fibers [14] [18].

The effect of chemical treatment, especially alkali and methacrylamide on the mechanical properties of SGF-reinforced polymer composites has been studied earlier [13] [14] [15] [16] [17]. These authors have shown that when the modified fiber is added to polymer matrix, the composites exhibit a significant increase in mechanical properties as compared to the untreated ones. In most of the reported literatures, different natural fibers, such as kenaf [23], jute [24], oil palm-EFB [25], bamboo [26], hemp [27], flax [28], banana [29] etc. have been used to reinforce PLA, where coupling agent and mercerization method for fiber surface treatment has been followed. Besides, to the best of our knowledge, the acetylation and the benzoylation method as well as ultrasonication of SGF have not yet been applied before to observe the structures and properties of SGF reinforced polymer composites. The present study deals with preparation and property evaluation of SGF reinforced PLA bio-composites. In this work, the effect of alkalization, acetylation and benzoylation on the material and antibacterial activities of SGF-PLA composites has been compared and the best treatment method for fiber surface modification has been identified.

\section{Experimental}

\subsection{Materials}

PLA in pellet form was purchased from Titan chemical, Pasir Gudang, Malaysia. SGF were collected from rural area of Jamalpur district in Bangladesh. The as-received SGF were cut carefully to separate the outer mat core from the inner fiber core. Only the outer mat core was used in this study. Single fibers were separated by hand until fine particulate fibers were obtained. Promising chemical modifiers like sodium hydroxide $(\mathrm{NaOH})$ for alkalization, acetic acid $\left(\mathrm{CH}_{3} \mathrm{COOH}\right)$, acetic anhydride $\left[\left(\mathrm{CH}_{3} \mathrm{CO}\right)_{2} \mathrm{O}\right]$ and sulphuric acid $\left(\mathrm{H}_{2} \mathrm{SO}_{4}\right)$ for acetylation, and benzoyl chloride $\left(\mathrm{C}_{6} \mathrm{H}_{5} \mathrm{COCl}\right)$ and Ethanol $\left(\mathrm{C}_{2} \mathrm{H}_{5} \mathrm{OH}\right)$ for benzoylation were procured for treatment of SGF. 1,4-dioxane was purchased from the chemical market in Dhaka for dissolving PLA. All chemical compounds were the products of Merck, Germany.

\subsection{Methods}

\subsubsection{Surface Modification of Fibers}

\section{1) Alkalization}

SGF were cut into $10 \mathrm{~mm}$ length and were soaked in 5 and $10 \mathrm{wt} \%$ solution of $\mathrm{NaOH}$ at $30^{\circ} \mathrm{C}$ maintaining a liquor ratio of 20:1. The fibers were washed with distilled water to remove dirt and other water soluble impurities and then immersed in $\mathrm{NaOH}$ solution for $2 \mathrm{~h}$. They were washed several times with fresh water to remove $\mathrm{NaOH}$ solution sticking to the fiber surface, neutralized with dilute acetic acid solution and finally washed again with distilled water to maintain the $\mathrm{pH}$ value of 7 . The fibers were sonicated for $1 \mathrm{~h}$ at $50^{\circ} \mathrm{C}$ in an ultrasonic cleaner [model: VGT-1860QTD, MTI, USA] and then dried at room tempera- 
ture for $48 \mathrm{~h}$ followed by oven drying at $100^{\circ} \mathrm{C}$ for $6 \mathrm{~h}$.

\section{2) Acetylation}

$10 \mathrm{~g}$ dried SGF were immersed in distilled water for $15 \mathrm{~min}$, pressed out and then introduced in a Buchner funnel. The wet fibers were transferred to a stoppered bottle and covered with $150 \mathrm{ml}$ of glacial acetic acid. After being shaken occasionally for $1 \mathrm{~h}$, the fibers were pressed out as before. Then a solution of $10 \%$ acetic acid in distilled water and $1 \mathrm{ml}$ concentrated $\mathrm{H}_{2} \mathrm{SO}_{4}$ at $25^{\circ} \mathrm{C}$ was prepared. The SGF were kept in this solution. The mixture was shaken vigorously for about $1 \mathrm{~min}$ and then $50 \mathrm{ml}$ of 5 and $10 \mathrm{wt} \%$ acetic anhydride solution was added and again shaken vigorously for about $1 \mathrm{~min}$. The resultant solution was held $5 \mathrm{~min}$ at $25^{\circ} \mathrm{C}$. The SGF were sonicated for $1 \mathrm{~h}$ at $50^{\circ} \mathrm{C}$ in an ultrasonic cleaner. The SGF were then washed with distilled water. Finally, the fibers were dried at $60^{\circ} \mathrm{C}$ and then stored in desiccators.

\section{3) Benzoylation}

The SGF were initially alkaline pre-treated in order to activate the hydroxyl groups of the cellulose and lignin in the fibers. Then the fibers were suspended in $10 \% \mathrm{NaOH}$, and 5 and $10 \mathrm{wt} \%$ solution of benzoyl chloride for $15 \mathrm{~min}$. The isolated fibers were then soaked in ethanol for $1 \mathrm{~h}$ to remove the benzoyl chloride. Then the fibers were sonicated for $1 \mathrm{~h}$ at $50^{\circ} \mathrm{C}$ in an ultrasonic cleaner. Finally, the fibers were washed with distilled water and dried in an oven at $80^{\circ} \mathrm{C}$ for $24 \mathrm{~h}$.

\subsubsection{Sample Preparation}

\section{1) Preparation of neat PLA foam}

In a beaker, neat PLA was dissolved in 1,4-dioxane by stirring with a magnetic stirrer and heating simultaneously. After 20 - 30 minutes the solvent is turned into viscous form. The viscous material was placed in a square shaped pot. After cooled in normal temperature the pot was placed in a refrigerator at $-20^{\circ} \mathrm{C}$. After $24 \mathrm{~h}$ the sample was shifted to the vacuum dryer. After $24 \mathrm{~h}$ the sample was removed from the dryer and obtained as foam. The prepared neat PLA foam is here-in-after abbreviated as PLAF.

\section{2) Composite preparation}

The composites were prepared by solution mixing with SGF and PLA pellets dissolved in 1,4-dioxane by stirring using a magnetic stirrer and heating simultaneously. The prepared composites are coded as untreated fiber reinforced PLA composites (UFPC), alkali treated fiber reinforced PLA composites (ALT-FPC), acetic-anhydride treated fiber reinforced PLA composites (ACT-FPC) and benzoyl-chloride treated fiber reinforced PLA composites (BCT-FPC). The composites, prepared with fibers treated at $5 \mathrm{wt} \%$ chemical concentrations are here-in-after indicated as 5ALT-FPC, 5ACT-FPC and 5BCT-FPC, and that prepared with fibers treated at $10 \mathrm{wt} \%$ chemical concentrations are here-in-after indicated as 10ALT-FPC, 10ACT-FPC and 10BCT-FPC. 5 and $10 \mathrm{wt} \%$ chemically modified fiber reinforced composites are here-in-after introduced as 5TFPCs and 10TFPCs, respectively. In all of these composites the fiber content is $5 \mathrm{wt} \%$. 


\section{Evaluation Methods}

\subsection{Water Intake Observation}

Water intakes of the composites were measured according to ASTM: C-67-91. The test specimens were cut in a size of $6 \mathrm{~cm}$ length, $2 \mathrm{~cm}$ width and $0.5 \mathrm{~cm}$ thickness. The cut samples were kept in an oven at $80^{\circ} \mathrm{C}$ for $24 \mathrm{~h}$. It was taken out from the oven and immediately weighed. Let this weight be $W_{i}$. The samples were then immersed in distilled water of $23^{\circ} \mathrm{C}$ and kept for $24 \mathrm{~h}$. It was taken out from the water, wiped by a cloth, dried in air and then weighed. Let this weight be $W_{f}$ Then the amount of water intake was calculated by the following formula:

$$
\text { Water intake }(\%)=\left[\frac{W_{f}-W_{i}}{W_{f}}\right] \times 100
$$

The above procedures were repeated for 2 days to 30 days for all samples. It is noteworthy that the cut sides of the samples were coated with araldite to prevent from penetrating water into the sample.

\subsection{Soil Burial Test}

The degradation under soil of the composites was performed according to ASTM: G-160. For this method, the samples were kept in an oven at $80^{\circ} \mathrm{C}$ for 24 h. It was taken out from the oven and immediately weighed. Let this weight be $w_{i}$. The samples were then buried under soil kept in a pot. The pot was covered with a plastic net and exposed to atmospheric conditions for 7 days. Readings were taken of the changes in the weight loss of the samples at intervals of 7 days for approximately one month. To determine the weight loss the specimen of each sample was taken out from the soil, wiped by a dry cloth or tissue paper, quickly washed with cold water and dried in an oven at $80^{\circ} \mathrm{C}$ to a constant weight. Let this weight be $w_{f}$ Then the percentage of weight loss was calculated by the following formula:

$$
\text { Weight loss }(\%)=\left[\frac{w_{i}-w_{f}}{w_{i}}\right] \times 100
$$

\subsection{Fourier Transforms Infrared Spectroscopy}

Fourier Transform Infrared (FTIR) spectra of the samples were recorded at room temperature by using a double beam IR spectrophotometer (model: Frontier, FT-IR/NIR Spectrometer, PerkinElmer, Japan) in the wave number range of $650-4000 \mathrm{~cm}^{-1}$. For these measurements, the samples were crushed for recording the attenuated total reflectance (ATR)-FTIR spectra in the transmittance (\%) mode.

\subsection{X-Ray Diffraction Technique}

The Bruker D8 ADVANCE XRD was used for taking pattern of X-ray diffraction 
(XRD). In this machine, a high voltage power supply ( $35 \mathrm{kV}, 20 \mathrm{~mA}$ ) was used to generate $\mathrm{X}$-ray radiation. The composites were finely ground to prepare the disc specimen of same thickness for each category of samples. $1 \mathrm{~g}$ chopped samples were compressed in a cylindrical mold with a pressure of $1 \mathrm{MPa}$. The samples were step-wise scanned by XRD over the operational range of scattering angle between $10^{\circ}$ to $30^{\circ}$, with a step of $0.02^{\circ}$, using the $\mathrm{CuK}_{\alpha}$ radiation of wavelength $\lambda=1.5406 \AA$. The data were recorded in terms of the diffracted X-ray intensity (I) versus $2 \theta$. The relative intensity is calculated by the following equation:

$$
I=\frac{I_{T F P C}}{I_{U F P C}}
$$

\subsection{Compressive Strength Test}

Compressive strength (CS) tests of PLAF, UFPC and differently treated fiber reinforced PLA composites (TFPCs) were performed by a universal testing machine (UTM) (model: H10KS, Hounsfield, UK) following ASTM: D-638-98 at a crosshead speed of $1 \mathrm{~mm} / \mathrm{min}$, keeping a gauge length of $10 \mathrm{~mm}$. The CS values were calculated by the following equation:

$$
\text { Compressive strength, } C S=P / A
$$

where $P=$ Maximum load applied to the sample, $A=$ Area of the sample (for the four-sided specimen, $A=\mathrm{LW}$, where $L$ is the length and $W$ is the width of the sample).

\subsection{Field Emission Scanning Electron Microscopy}

The fractured samples of PLAF, UFPC and TFPCs obtained from the compressive strength tests were examined using a field emission scanning electron microscope (FESEM) (model: JSM-7600F, Jeol, Japan) at an acceleration potential of $20 \mathrm{kV}$. The fractured surfaces of the specimens were sputter-coated with a thin layer of platinum using a JFC-1600 auto fine coater.

\subsection{Thermal Test}

Thermo gravimetric analyzer (TGA) coupled with a differential thermal analyzer (DTA) (model: EXSTAR, TG/DTA 6300, Seiko, Japan) was used in this study. The samples were heated from room temperature up to $600^{\circ} \mathrm{C}$ in a nitrogen atmosphere at a heating rate of $20^{\circ} \mathrm{C} / \mathrm{min}$. TGA is used primarily for determining thermal stability of samples. Data are recorded as thermograms of weight versus temperature.

\subsection{Antibacterial Activity Test}

Antibacterial activities of UFPC, ALT-FPC, ACT-FPC and BCT-FPC were measured against Gram-negative bacteria Escherichia coli and Gram-positive bacteria Staphylococcus aureus with agar diffusion method by Kirby-Bauer, 1985 [30]. 


\subsection{Cytotoxic Effect Test}

Cytotoxic effect of the samples was also examined. Vero cell line, kidney epithelial cells extracted from an African green monkey, was maintained in Dulbecco's modified eagles' medium (DMEM) containing $1 \%$ penicillin-streptomycin (1:1) and $0.2 \%$ gentamycin and $10 \%$ fetal bovine serum (FBS). Cells $(3.7 \times$ $\left.10^{4} / 250 \mu \mathrm{l}\right)$ were seeded onto 48 -well plates and incubated at $37^{\circ} \mathrm{C}+5 \% \mathrm{CO}_{2}$. Next day, autoclaved samples were added to each well. Cytotoxicity was examined under an inverted light microscope after $72 \mathrm{~h}$ of incubation. Duplicate wells were used for each sample.

\section{Results and Discussion}

\subsection{Water Intake}

Figure 1(a) and Figure 1(b) show the variation of water intake (WI) on soaking time for PLAF, UFPC and different TFPCs. WI increases rapidly at the initial stage and nearly levels off after 10 days for UFPC and after 15 days for TFPCs. These results indicate that the absorption of water is slower for TFPCs than UFPC. $W I$ is more in UFPC followed by BCT-FPC, ACT-FPC, ALT-FPC for both 5 and $10 \mathrm{wt} \%$ treated fiber reinforced composites, and PLAF. Although it is observed that $W I$ value of 5TFPCs is higher than that of 10TFPCs. Untreated SGF is hydrophilic in nature and as a result $W I$ is found to be more in UFPC than that of TFPCs and PLAF. After treatment, the hydrophilicity of the treated fiber decreases as well as a good adhesion of fiber with polymer matrix is established. Consequently WI of TFPCs decreases, as also reported elsewhere [31]. The maximum WI obtained in this study is $43.76 \mathrm{wt} \%$ for UFPC.

\subsection{Weight Loss}

The degradation of composites has been evaluated by measuring the weight loss of samples, which have been soil buried in outdoor for 28 days. Figure 2(a) and Figure 2(b) illustrate the weight loss ( $W L$ ) of PLAF, UFPC and different TFPCs as a function of the degradation time. As represented, all composites show an increased degradation rate during the buried process. This is likely a result of the penetration of moisture into the composites, causing the hydrolysis of surfaces and interfaces [32]. After 28 days coverage, the $W L$ of samples reaches 36.06 wt\% for PLAF, $40.98 \mathrm{wt} \%$ for UFPC, and 44.92, 47.44 and $45.84 \mathrm{wt} \%$ for 5ALT-FPC, 5ACT-FPC and 5BCT-FPC, respectively. Moreover, the $W L$ is found $50.49,47.75$ and $49.44 \mathrm{wt} \%$ for 10ALT-FPC, 10ACT-FPC and 10BCT-FPC, respectively. These results suggest that the degradability of composites is slightly higher than that of PLAF. Apparently, the degradability of composites as compared to that of the PLAF is not swift but is slow, which is expected from bio-composites so that they can substitute the non-degradable composite materials [25]. 

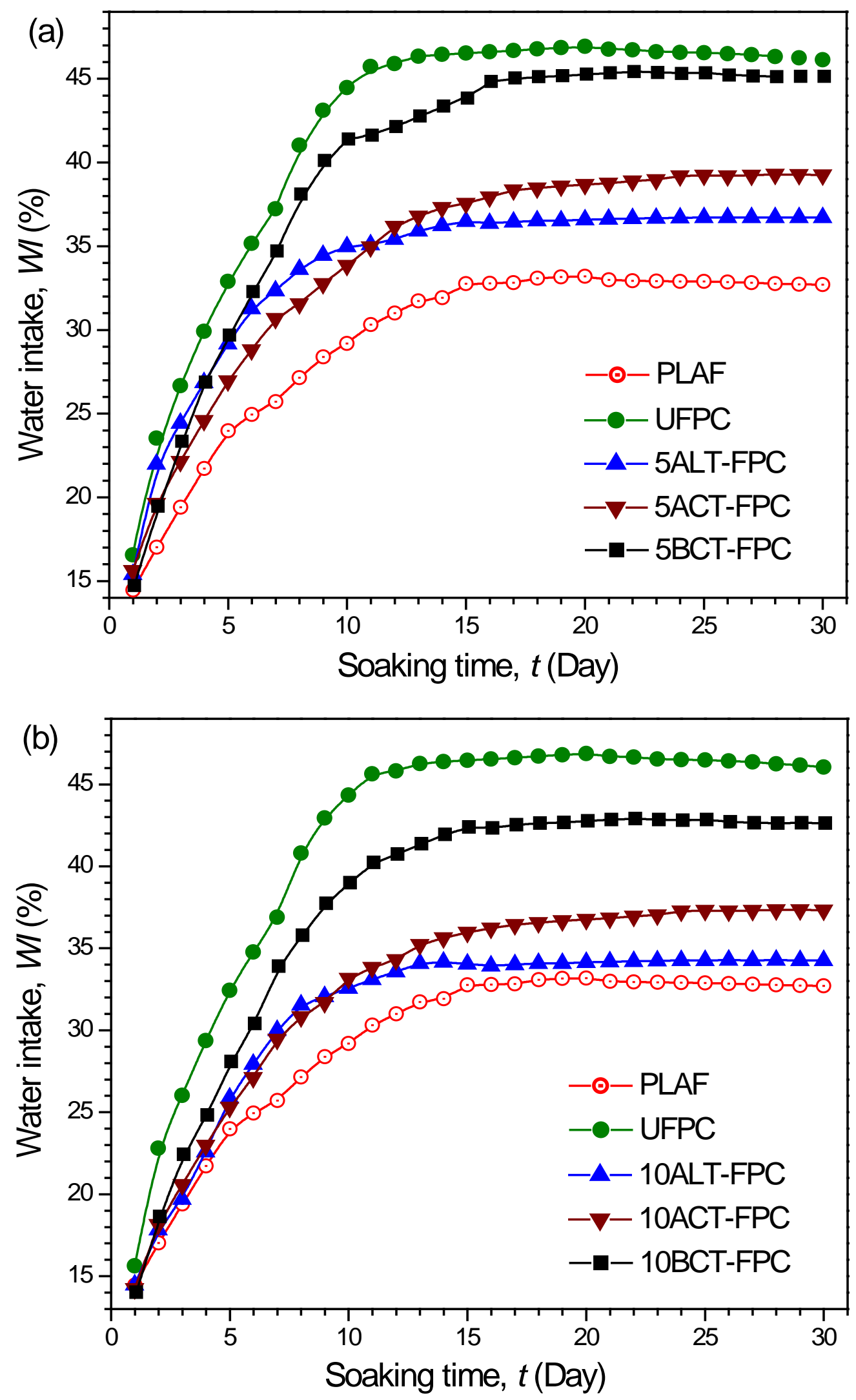

Figure 1. The variation of water intake on soaking time for PLAF, UFPC, and different TFPCs for (a) $5 \mathrm{wt} \%$ and (b) $10 \mathrm{wt} \%$ chemical concentration. 

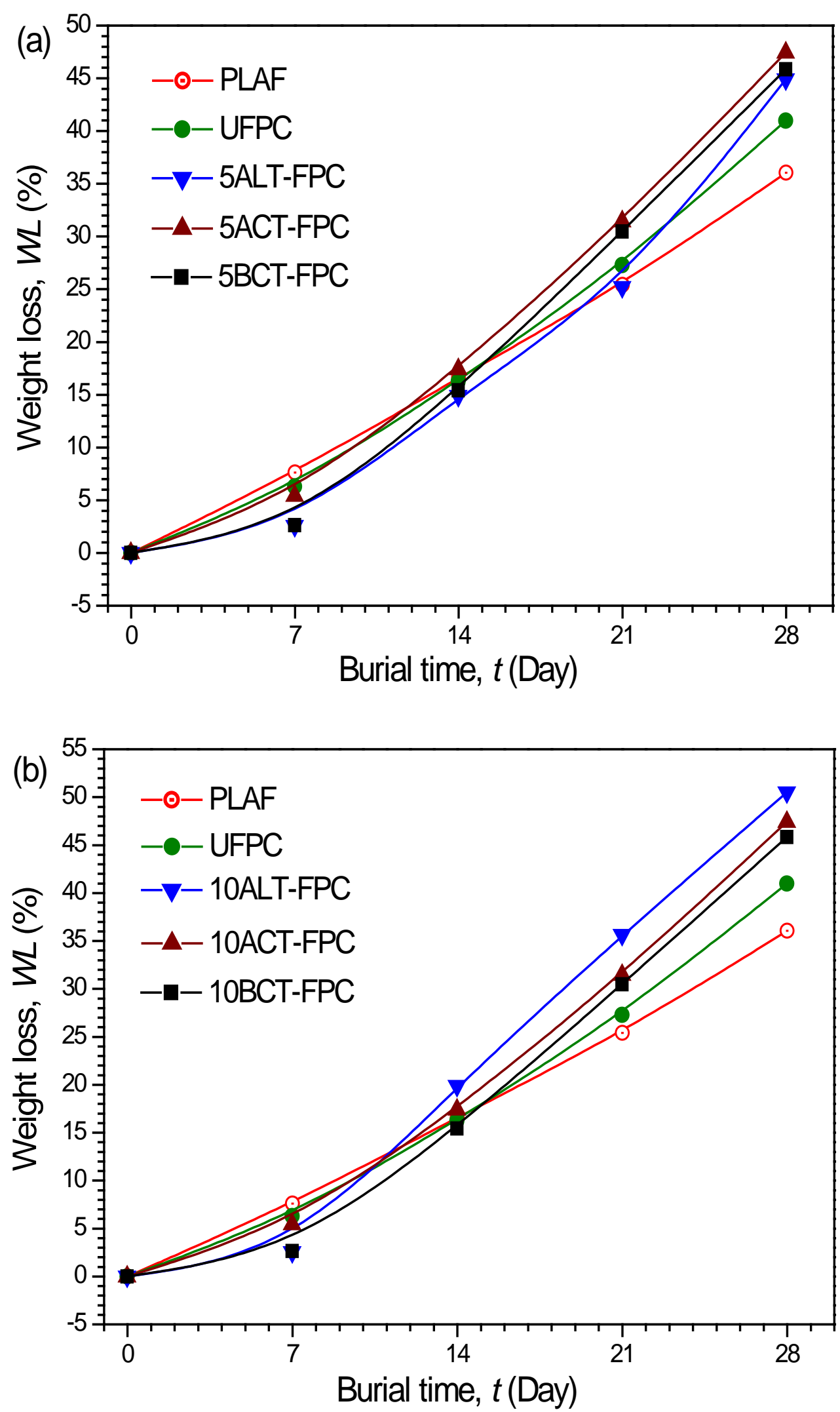

Figure 2. Variation of weight loss by soil degradation with burial time for the PLAF, UFPC, and different TFPCs for (a) $5 \mathrm{wt} \%$ and (b) $10 \mathrm{wt} \%$ chemical concentration. 


\subsection{FTIR Structural Analyses}

The ATR-FTIR spectra of the PLAF, UFPC, ALT-FPC, ACT-FPC and BCT-FPC are shown in Figure 3(a) and Figure 3(b), and Figure 4(a) and Figure 4(b) for the treatment concentration of 5 and $10 \mathrm{wt} \%$, respectively. There is no notable
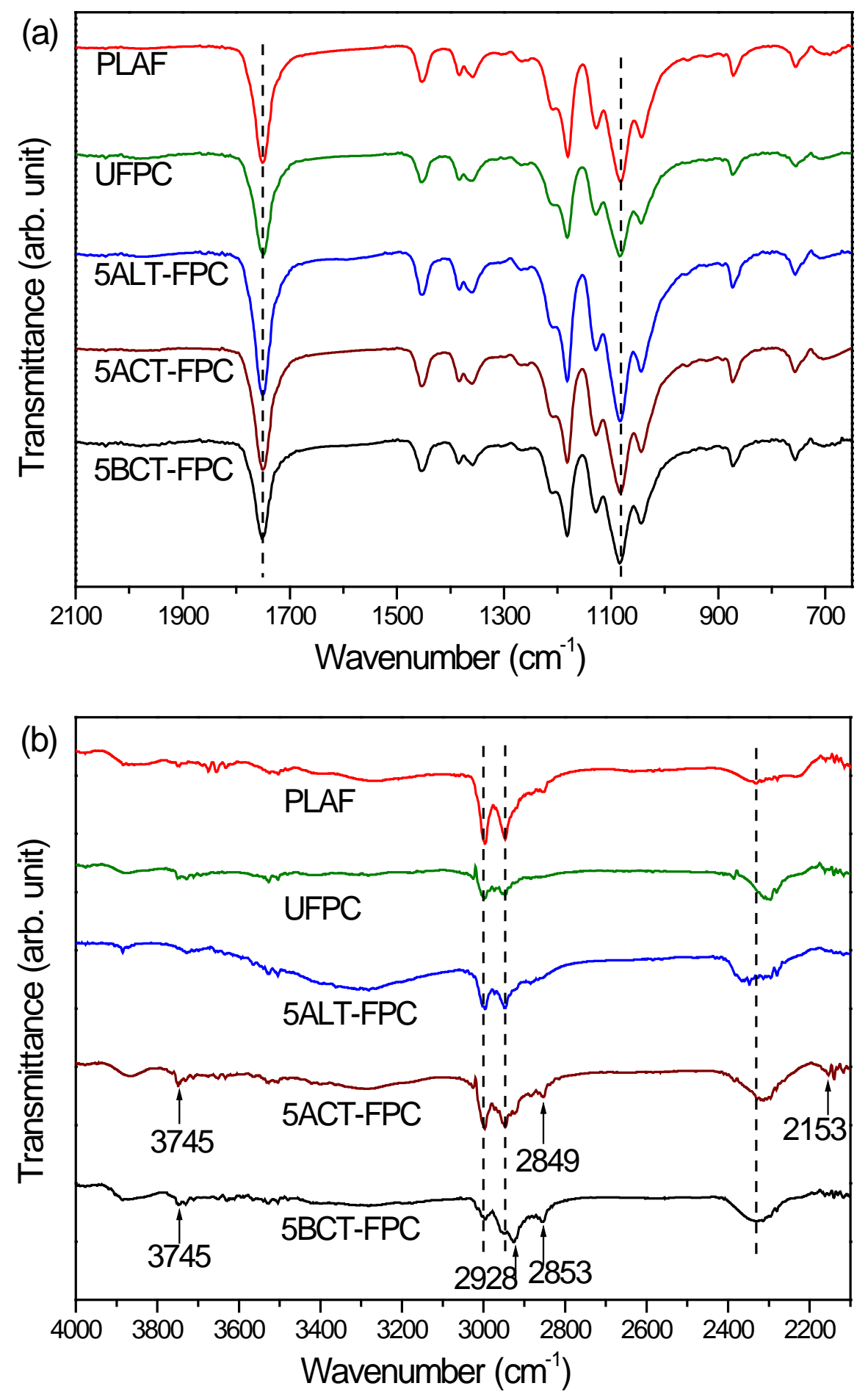

Figure 3. FTIR spectra of PLAF, UFPC, 5ALT-FPC, 5ACT-FPC, and 5BCT-FPC from the wavenumber range (a) $650-2100 \mathrm{~cm}^{-1}$ and (b) $2100-4000 \mathrm{~cm}^{-1}$. 

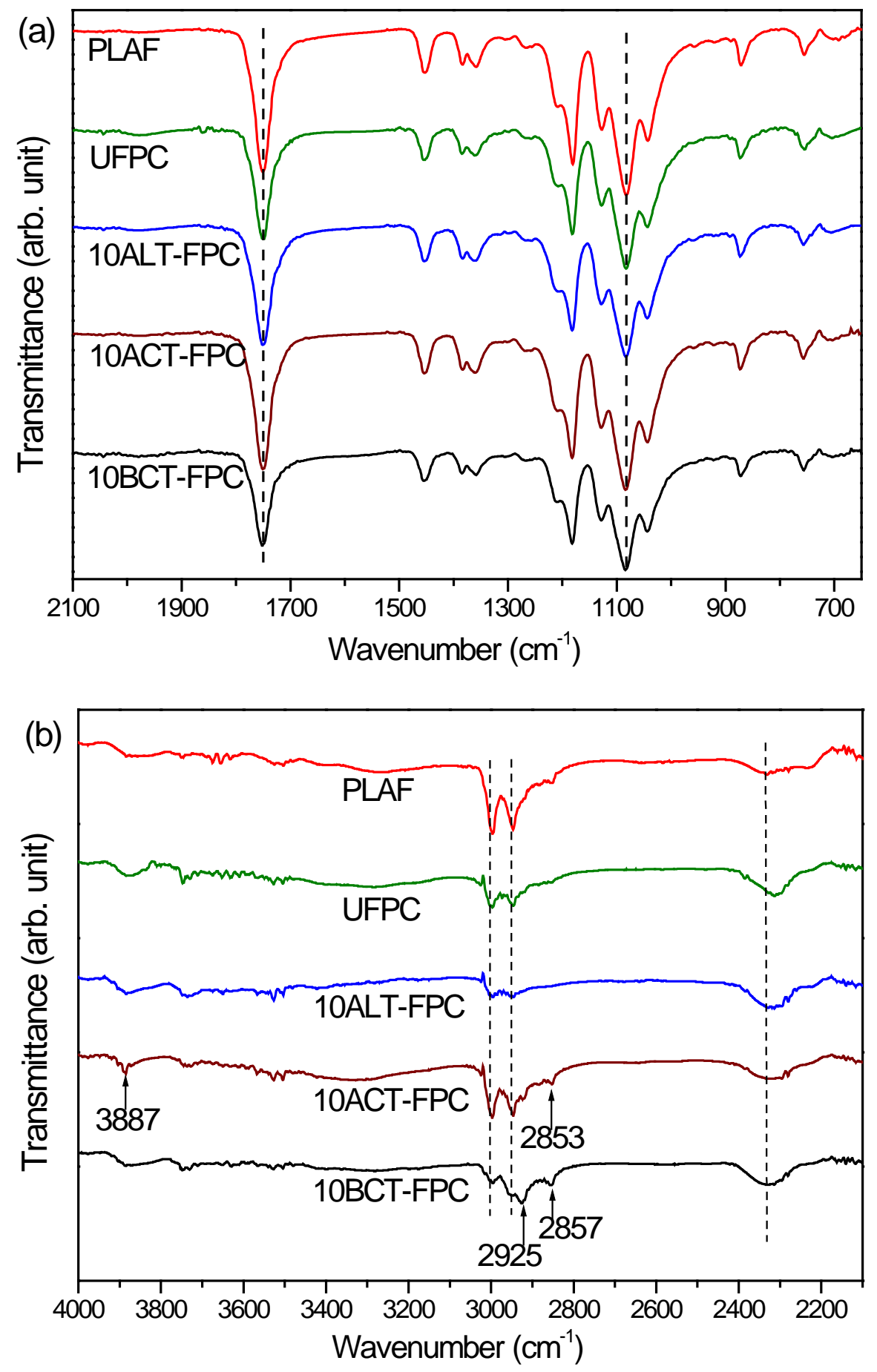

Figure 4. FTIR spectra of PLAF, UFPC, 10ALT-FPC, 10ACT-FPC, and 10BCT-FPC from the wavenumber range (a) $650-2100 \mathrm{~cm}^{-1}$ and (b) $2100-4000 \mathrm{~cm}^{-1}$.

variation in the FTIR spectra of Figure 3(a). The peaks at the range of 1000 $1300 \mathrm{~cm}^{-1}$ from the skeletal stretching vibrations may include the $\mathrm{C}-\mathrm{C}$ axial elongation and $\mathrm{C}-\mathrm{N}$ stretching of amines of the samples. On the other hand, there are some variations in the spectra of Figure 3(b). The main transmittance peaks in this study have been identified. The first notable variation is found at 
the peak for 5ACT-FPC as shown by an arrow at $2153 \mathrm{~cm}^{-1}$, which corresponds to the characteristic $\mathrm{C}=\mathrm{O}$ stretching vibration. The peak at $2849 \mathrm{~cm}^{-1}$ for 5ACT-FPC and $2853 \mathrm{~cm}^{-1}$ for 5BCT-FPC are the characteristic bands for the $\mathrm{C}-\mathrm{H}$ stretching vibration. The transmittance peak at $2928 \mathrm{~cm}^{-1}$ of 5BCT-FPC may be belong to the $\mathrm{O}-\mathrm{H}$ stretching vibration of linkage of carboxylic acid in lignin or ester group in hemicellulose. In Figure 4(a), there is also any remarkable variation is absent. But in Figure $4(\mathrm{~b})$, a clear change is notable in the transmittance peak for 10ACT-FPC. The sharp peak at $2153 \mathrm{~cm}^{-1}$ of 5ACT-FPC [Figure 3(b)] is removed at the stage of 10ACT-FPC [Figure 4(b)] indicates removing of $-\mathrm{C}=\mathrm{O}$ stretching vibration band.

From the above stated experiment of FTIR, especially from Figure 3(b) and Figure $4(\mathrm{~b})$ it is notable that the acetic anhydride and benzoyl chloride may have interacted chemically with SGF.

\subsection{Crystalline Structure}

The XRD patterns of PLAF, UFPC, ALT-FPC, ACT-FPC and BCT-FPC are illustrated in Figure 5(a) and Figure 5(b) for the treatment concentration of 5 and $10 \mathrm{wt} \%$, respectively. The two sharp diffraction peaks of PLAF and composites come from the component PLA at the scattering angle $2 \theta=16.50^{\circ}$ to $18.80^{\circ}$. The very small XRD peak of treated SGF appears at $22.30^{\circ}$ as indicated by arrow. The position of first peak is shifted to slightly higher angle in alkali treated sample in both 5 and $10 \mathrm{wt} \%$, indicating a decrease in interplanar spacing of PLA crystal. The relative intensities have been estimated to be $I_{1}=1.57, I_{2}=1.02$, and $I_{3}=$ 1.08 for 5TFPCs, and $I_{4}=1.62, I_{5}=1.61$, and $I_{6}=1.32$ for 10TFPCs, respectively. Thus, it is clear that the intensity of the first and second peaks increases by fiber treatment, suggesting an increase in crystallinity of the modified composites. The results also suggest that a close packing takes place in the PLA crystal possibly by the crystal nucleation effect of cellulose molecules after removal of hemicellulose, lignin, pectin, etc. by different treatments. These results are similar to the reported results [33]. Among these samples, the crystallinity is better for 5ALT-FPC than others.

\subsection{Compressive Strength}

The compressive strength (CS) test results for PLAF, UFPC, and 5 and 10TFPCs are shown in Figure 6(a) and Figure 6(b), respectively. In all of the samples the strength of UFPC is the least of value, which is 7.61 MPa. On the other hand, the results indicate that there is a notable increase in CS of composites with the treatment of fibers. The CS values for 5ALT-FPC, 5ACT-FPC and 5BCT-FPC are $8.35,8.59$ and $10.06 \mathrm{MPa}$, respectively, and for 10ALT-FPC, 10ACT-FPC and 10BCT-FPC are 9.7, 9.97 and 9.89 MPa, respectively. The highest strength is found for 5BCT-FPC having the value of $10.06 \mathrm{MPa}$.

In all of the composites, the CS value is found to increase by $10 \%-35 \%$ after chemical treatment. This increase can be attributed to the reduction in the 

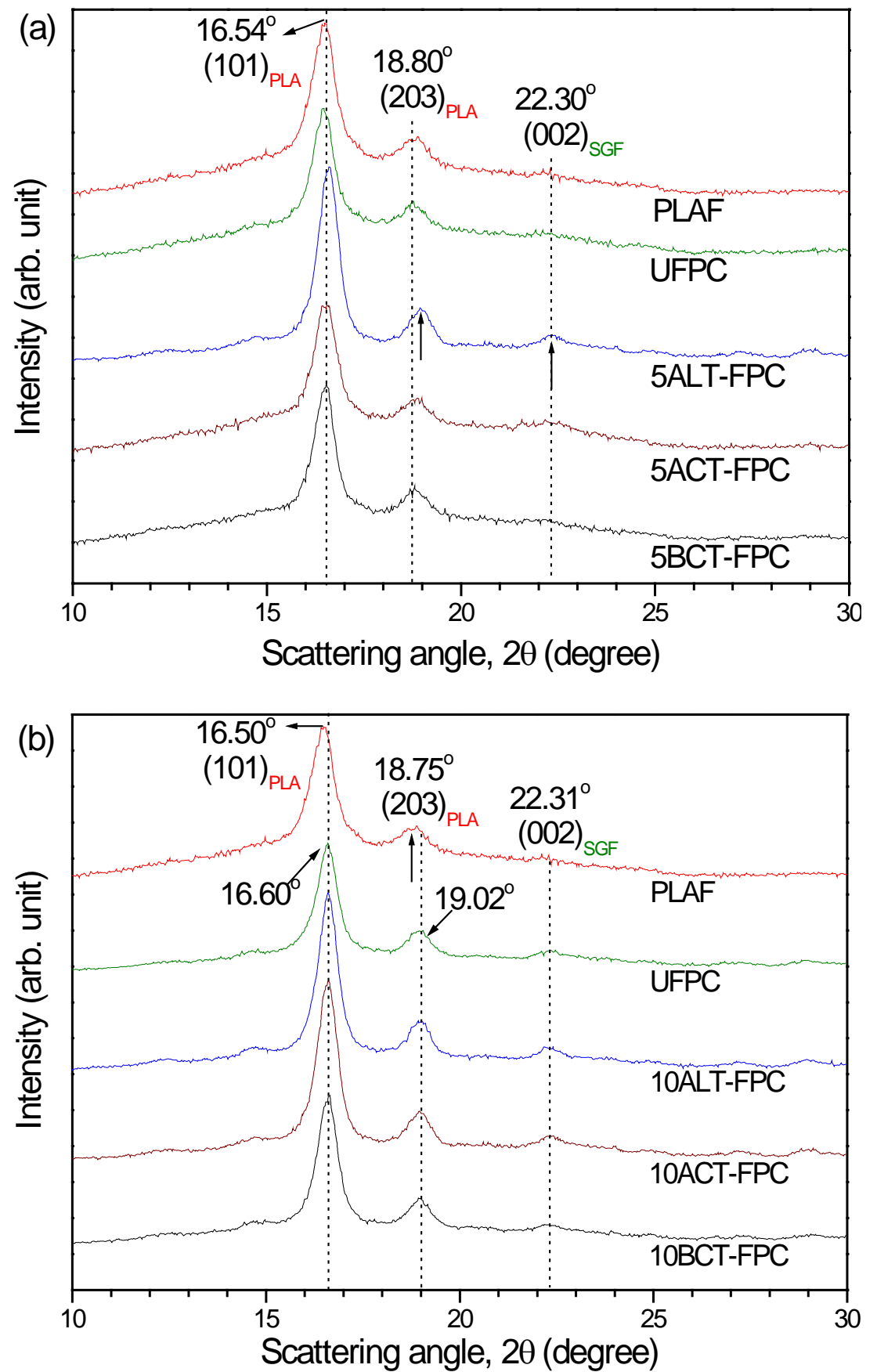

Figure 5. Wide angle XRD profiles of PLAF, UFPC, ALT-FPC, ACT-FPC, and BCT-FPC for the chemical concentration of (a) $5 \mathrm{wt} \%$ and (b) $10 \mathrm{wt} \%$.

porosity of foam type PLA and an enhancement in mechanical bond strength [34]. It is observed that the formation of cracks is extended in the specimens without fibers. However, the increase in CS due to SGF inclusion can be attributed to the improvement in the mechanical bond strength between the fibers and matrix where the fibers contribute to delay of micro-crack formation and stop their propagation afterwards up to a certain extent of fibers volume fraction [35] [36]. 

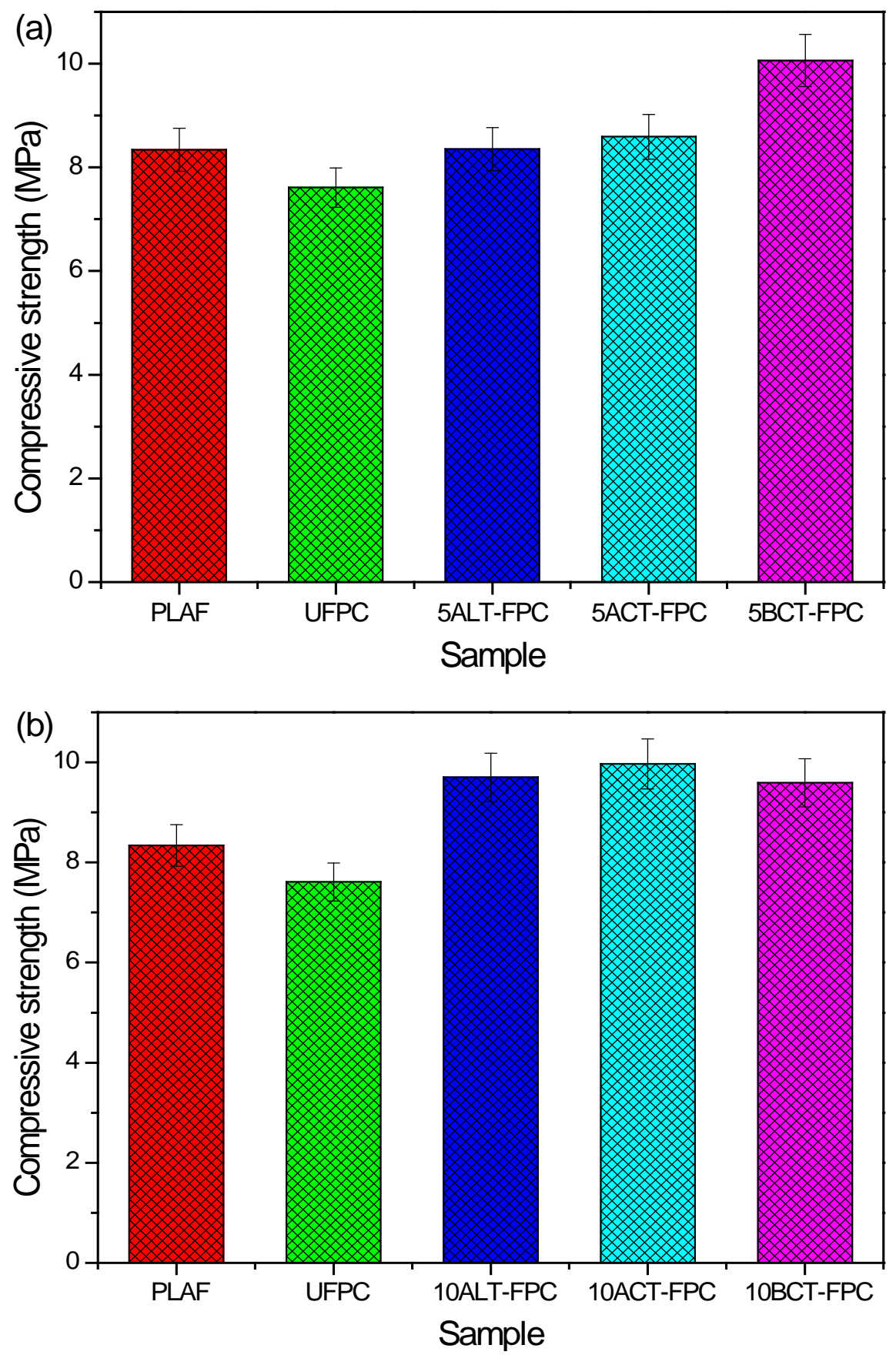

Figure 6. Compressive strength values for PLAF, UFPC, and different TFPCs for (a) 5 wt $\%$ and (b) $10 \mathrm{wt} \%$ chemical concentrations.

\subsection{Surface Morphology}

Figure 7 illustrates FESEM micrograph of the fractured surface of (a) PLAF and (b) UFPC. The surfaces of both images are not fairly smooth. The porosity of PLA increases when it is made PLAF. Besides, a lot of flaws and voids are seen on the surface of PLAF. In Figure 7(b), the image of UFPC shows lot of weak interfaces, resulting poor adhesion between fiber and matrix components. Huge pores are also found on the surface of UFPC. 
Figure 8(a), Figure 8(b) and Figure 8(c) represent FESEM micrographs of the fractured surfaces of 5ALT-FPC, 5ACT-FPC and 5BCT-FPC, respectively. Figure 8(a) shows that the impact between PLA matrix and SGF is moderate. It is clear that the surface of the 5ALT-FPC is slightly rough but smoother than that of PLAF and UFPC. In Figure 8(b) and Figure 8(c), it is remarkable that
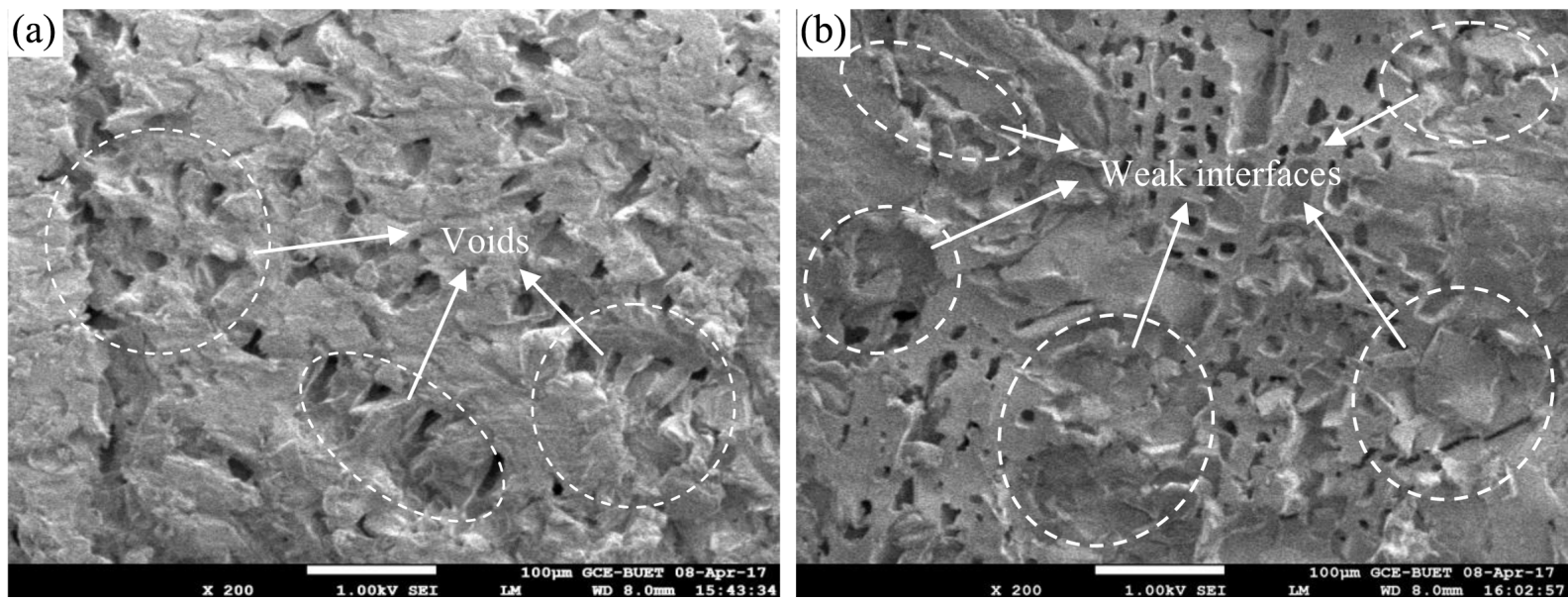

Figure 7. FESEM micrographs of the fractured surfaces by compressive strength test of (a) PLAF and (b) UFPC.
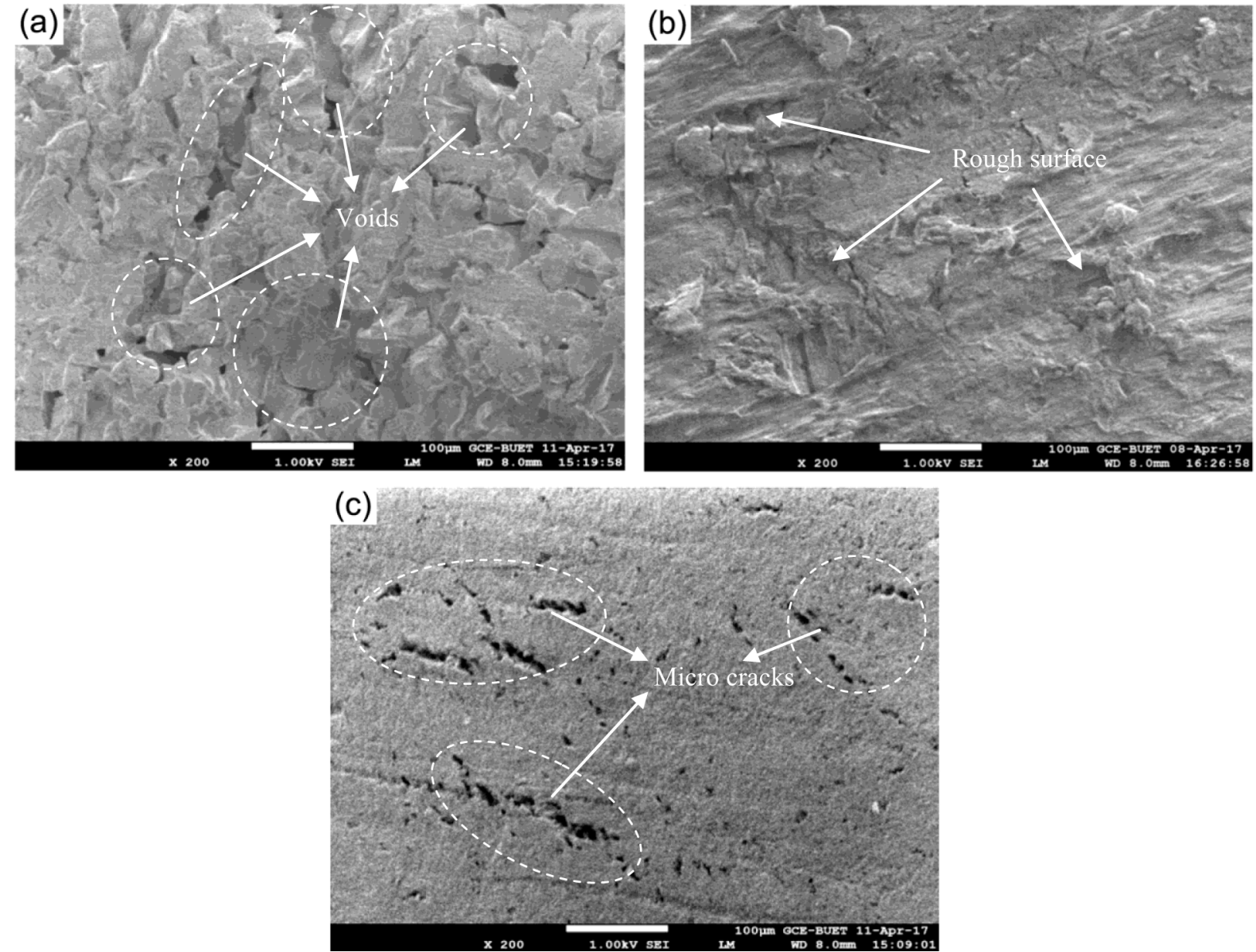

Figure 8. FESEM micrographs of the fractured surfaces of (a) 5ALT-FPC, (b) 5ACT-FPC, and (c) 5BCT-FPC. 
the interfacial adhesion between matrix and SGF powder is found to be improved. In Figure $8(\mathrm{c})$, it is seen that the surface is a little bit rough and some cracks are observed.

Figure 9(a), Figure 9(b) and Figure 9(c) represent the FESEM images of fractured surfaces of 10ALT-FPC, 10ACT-FPC and 10BCT-FPC, respectively. Figure 9(a) shows that the impact between fiber and matrix is good. It is clear that the surface of the 10ALT-FPC is smoother than 5ALT-FPC. In Figure 9(b) and Figure 9(c), it is clearly seen that the interfacial adhesion between PLA matrix and SGF powder of 10TFPCs are also found to be improved than that of 5TFPCs.

\subsection{Thermal Analyses}

Figure 10(a) and Figure 10(b) illustrate the thermograms for TGA of the PLAF, UFPC, and TFPCs for the treatment concentration of 5 and $10 \mathrm{wt} \%$, investigated in a temperature range of $35^{\circ} \mathrm{C}-600^{\circ} \mathrm{C}$. The on-set degradation for all samples occurs at higher temperature, precisely after $280^{\circ} \mathrm{C}$. The TGA sharp-fall occurs at different temperatures, depending on the samples. However, the
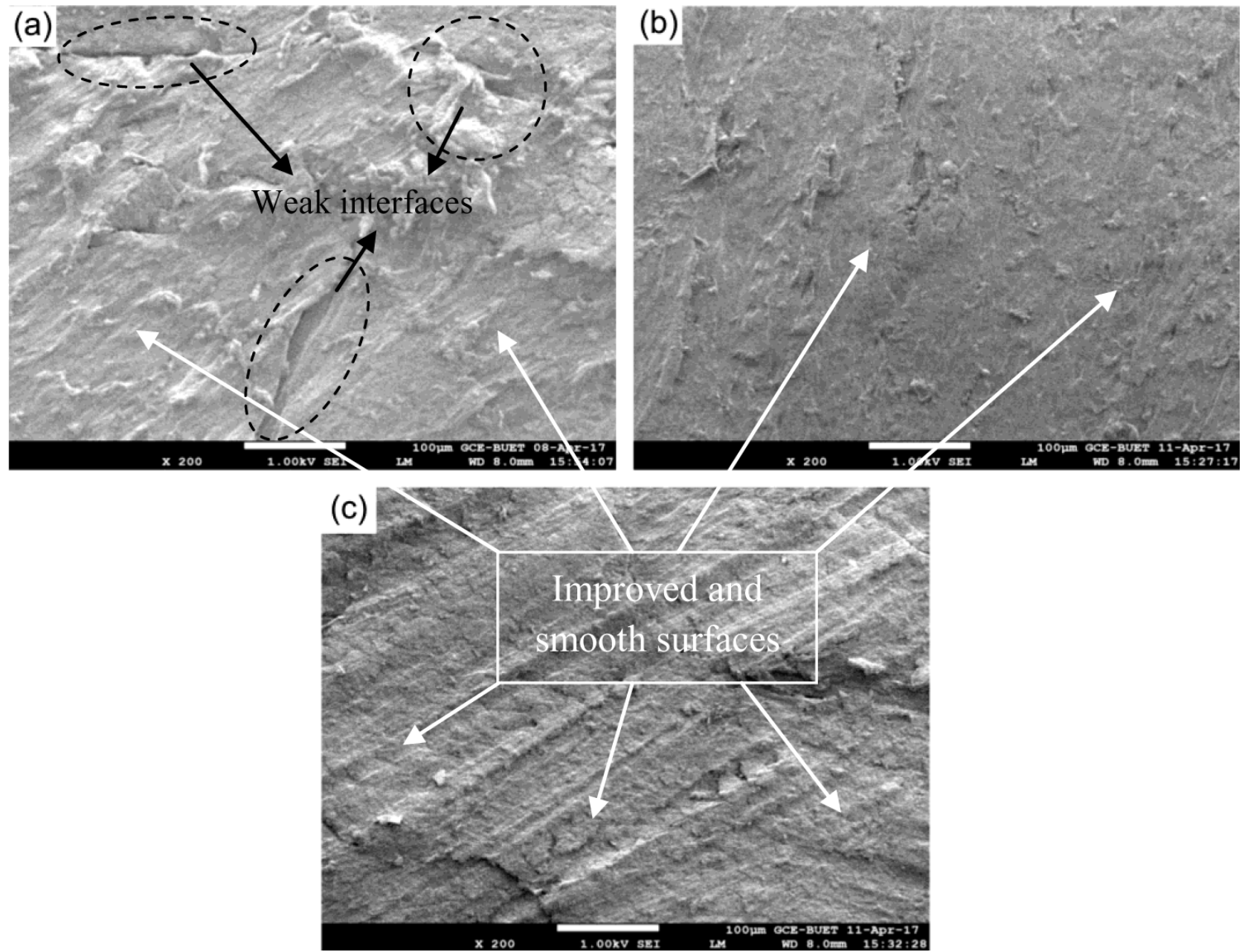

Figure 9. FESEM micrographs of the fractured surfaces of (a) 10ALT-FPC, (b) 10ACT-FPC, and (c) 10BCT-FPC. 

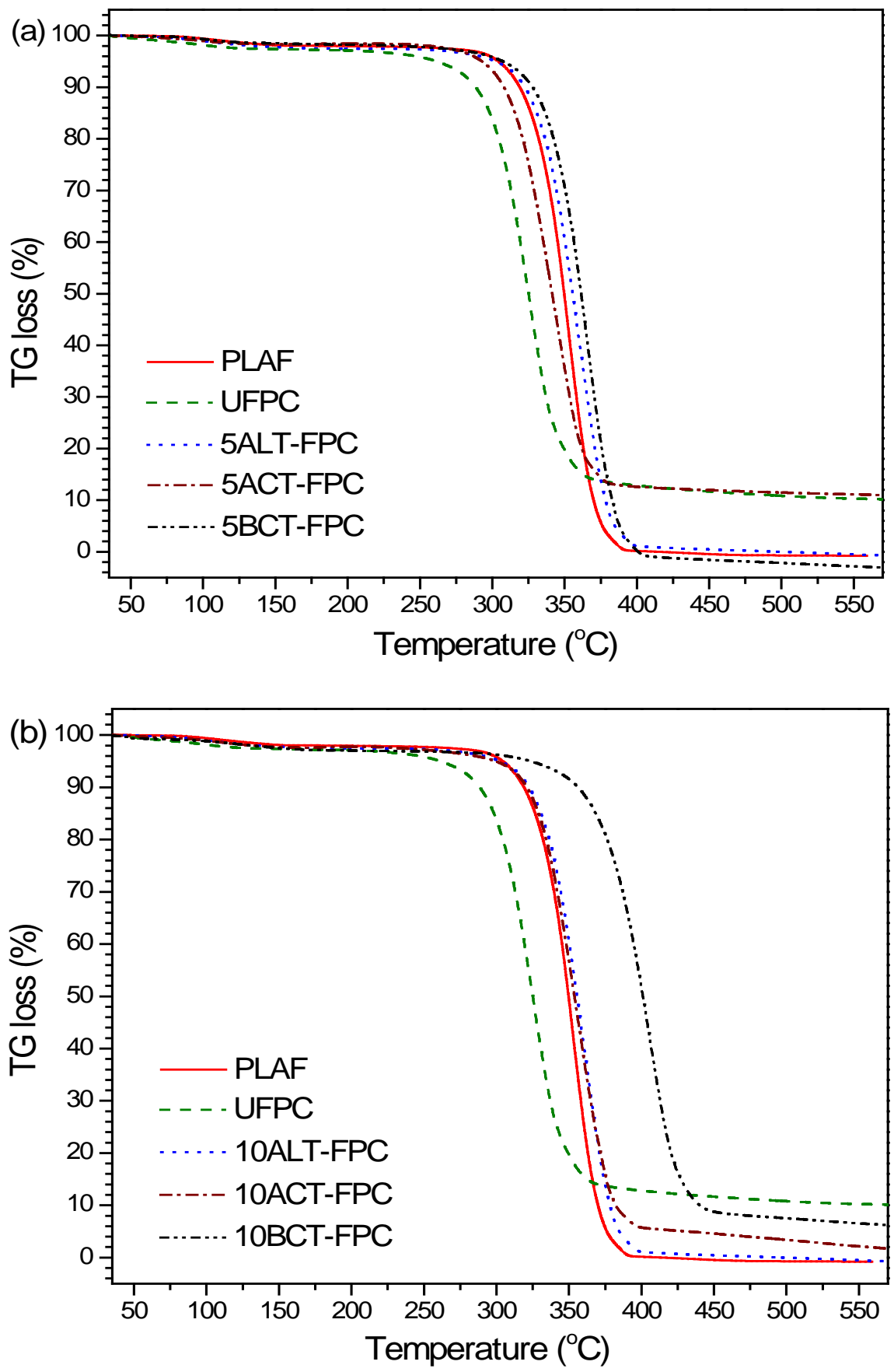

Figure 10. TGA thermograms for the sample of PLAF, UFPC, and different TFPCs for the chemical concentrations of (a) $5 \mathrm{wt} \%$ and (b) $10 \mathrm{wt} \%$.

temperature at $50 \%$ weight loss is considered as the thermally stable temperature for the sample [37]. The on-set temperature $\left(T_{o}\right)$, the stable temperature $\left(T_{S}\right)$, and the end-set temperature $\left(T_{e}\right)$ values evaluated from the TGA curves of the samples are introduced in Table 1.

Figure 11(a) and Figure 11(b) depict the DTA thermograms of PLAF, UFPC, and different TFPCs for 5 and $10 \mathrm{wt} \%$ chemical concentrations, investigated in a temperature range of $35^{\circ} \mathrm{C}-600^{\circ} \mathrm{C}$. The starting points of first endothermic 
Table 1. The $T_{o}, T_{s}$, and $T_{e}$ values obtained from TGA thermograms data.

\begin{tabular}{cccc}
\hline Sample & $T_{o}{ }^{\circ} \mathrm{C}$ & $T_{s}{ }^{\circ} \mathrm{C}$ & $T_{e}{ }^{\circ} \mathrm{C}$ \\
\hline PLAF & 315.58 & 349.80 & 370.74 \\
UFPC & 286.33 & 322.71 & 338.87 \\
5ALT-FPC & 323.77 & 356.72 & 380.02 \\
10ALT-FPC & 326.40 & 356.85 & 382.06 \\
5ACT-FPC & 303.93 & 353.93 & 379.04 \\
10ACT-FPC & 324.22 & 357.00 & 386.58 \\
5BCT-FPC & 331.85 & 363.85 & 386.92 \\
10BCT-FPC & 368.82 & 405.34 & 423.69 \\
\hline
\end{tabular}

From the results presented in Table 1, it is clearly seen that the sample 10BCT-FPC is thermally more stable than others.
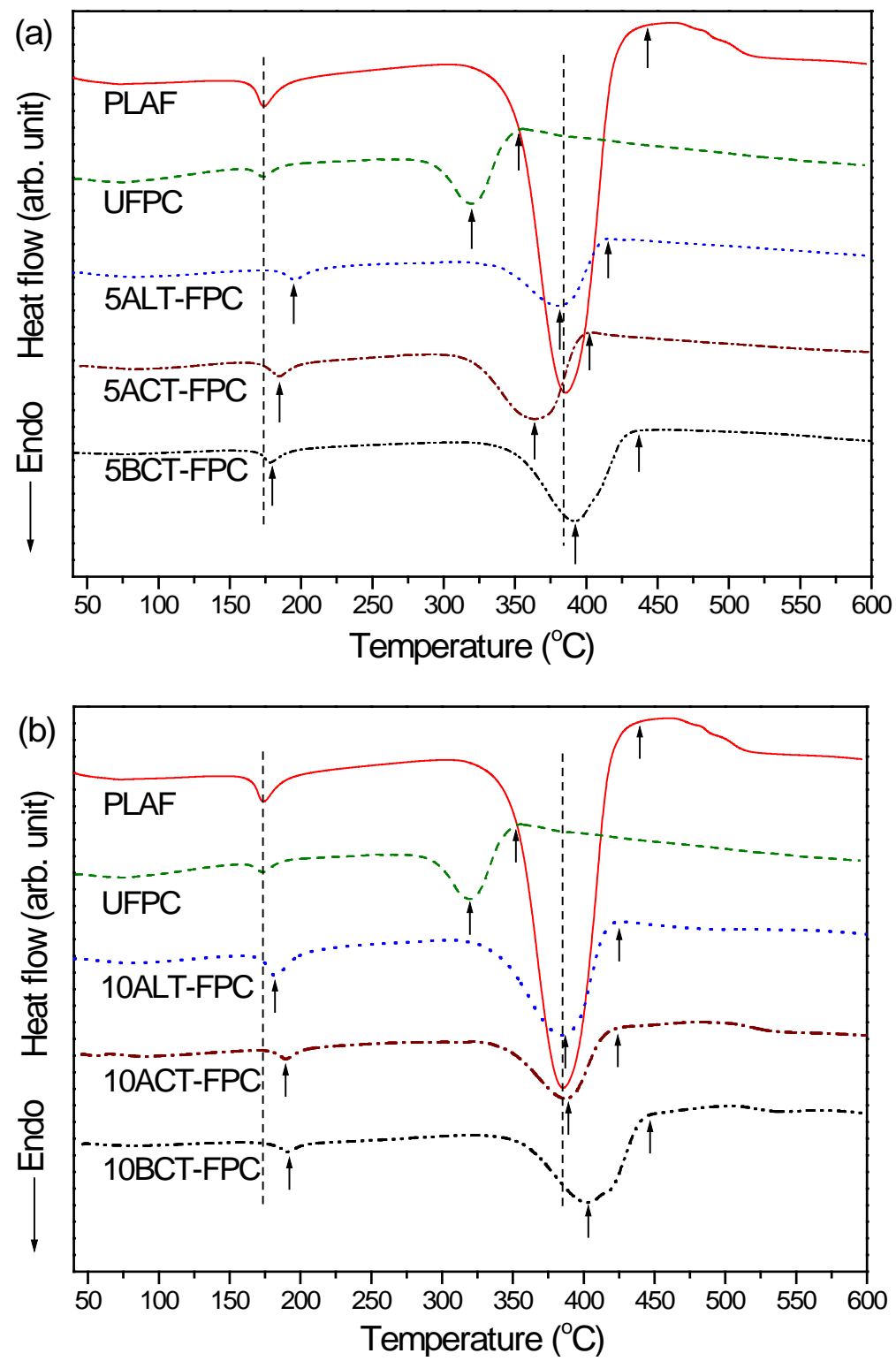

Figure 11. DTA curves for the sample of PLAF, UFPC, and different TFPCs of (a) $5 \mathrm{wt} \%$ and (b) $10 \mathrm{wt} \%$ treatment concentrations. 
peak of DTA for all samples indicate the melting temperature $\left(T_{m}\right)$ of the samples. The starting points of second endothermic peak correspond to the degradation temperatures $\left(T_{d}\right)$ of the samples. The DTA indicates that the $T_{m}$ value of 5ALT-FPC is more than others, but the $T_{d}$ value of $10 \mathrm{BCT}-\mathrm{FPC}$ is $404.41^{\circ} \mathrm{C}$, which appears as the highest value observed among the composites. The $T_{m}$ and $T_{d}$ values for different samples are inserted in Table 2.

The observed results strongly suggest that the benzoyl chloride treated fiber reinforced PLA composites are thermally more stable than others and the chemical treatments of SGF result in slow thermal decomposition. This may be connected to the different decomposition behaviors of the molecules of the differently treated SGF. The decomposition of the parent molecule, benzoyl chloride, is highly condition-dependent with the sample heating rate and temperature of decomposition playing a preponderant role in the course of the decomposition [38]. The degradation of SGF reinforced PLA composites have been ascribed by the dissociation of $\mathrm{C}-\mathrm{C}$ chain bonds along with $\mathrm{H}$-abstraction at the site of dissociation [39].

\subsection{Antibacterial Activities}

Figure 12 shows the antibacterial activities of the UFPC, 5ALT-FPC, 5ACT-FPC and 5BCT-FPC composites. Evaluation of antibacterial activities was carried out through dynamic shake flask method accompanying with plate count agar technique (Kirby-Bauer agar diffusion) using (a) E. coli and (b) S. aureus (Reference: FARL-72) as testing bacteria. Antibacterial properties of materials were accounted by comparative analysis of viable cell count from treated and untreated composites by means of bactericidal behavior. We have found that the antibacterial activity has decreased with the treatment of SGF. It is observed that there is no zone of inhibition surrounded the sample disc. Moreover, the used chemicals couldn't import antimicrobial properties to the composites. So, none of the samples have any antibacterial effect on E. coli and $S$. aureus.

Table 2. Melting and degradation temperature of PLAF, UFPC and different TFPCs.

\begin{tabular}{ccc}
\hline Sample & $T_{m}{ }^{\circ} \mathrm{C}$ & $T_{d}{ }^{\circ} \mathrm{C}$ \\
\hline PLAF & 173.43 & 385.38 \\
UFPC & 173.00 & 319.00 \\
5ALT-FPC & 195.85 & 384.00 \\
10ALT-FPC & 182.88 & 385.50 \\
5ACT-FPC & 184.70 & 363.74 \\
10ACT-FPC & 189.42 & 387.20 \\
5BCT-FPC & 180.00 & 391.80 \\
10BCT-FPC & 192.69 & 404.41
\end{tabular}




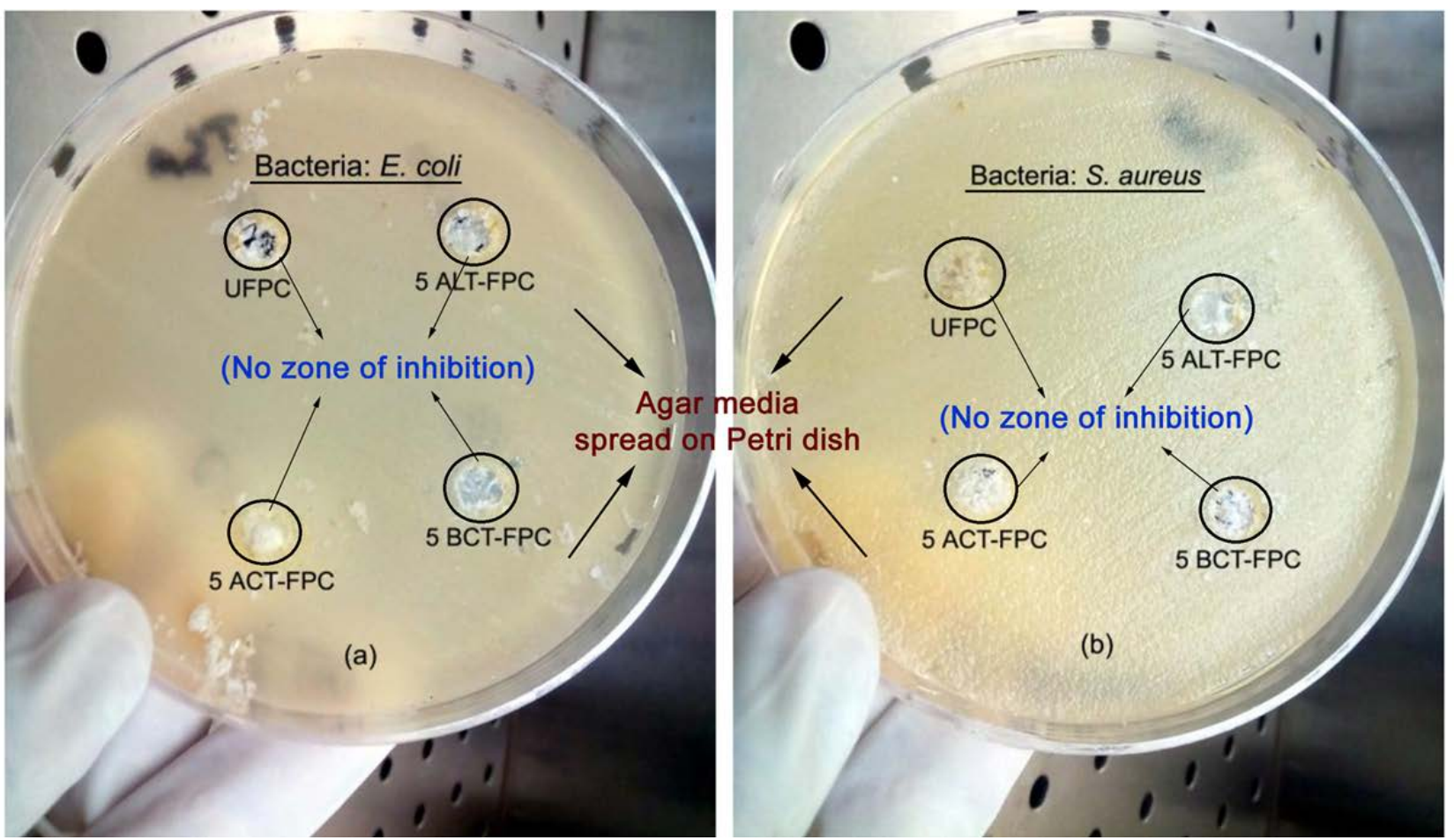

Figure 12. Images of antibacterial activity of UFPC, 5ALT-FPC, 5ACT-FPC and 5BCT-FPC on the bacteria (a) Escherichia coli and (b) Staphylococcus aureus.

\subsection{Cytotoxicity of the Composites}

Figure 13 shows the cytotoxic effect of only treated samples like 5ALT-FPC, 5ACT-FPC and 5BCT-FPC composites. All of the samples were tested on the category of Vero cell (non-cancer cell) line. The results collected after $72 \mathrm{~h}$ from the time of sample placement. The test results are summarized in Table 3.

The protocols in this research describe the growth and maintenance of Vero cells using DMEM as the culture medium. The DMEM is a very common culture medium, but a variety of other media can also be successfully used with Vero cells. Depending on the application, it may be desired or necessary to count the number of cells (i.e., if a specific number of cells need to be analyzed, plated, etc.). The concentration of cells in suspension (following trypsin treatment) was determined using a hemacytometer. In this Figure, the black shadows indicated the amount of death cells and the light colors indicated the survivor cells. The images proof that the prepared samples are not harmful for non-cancer cell of human body.

\section{Conclusion}

The chemical modifications of SGF have accelerated the degradation under soil of the SGF-PLA composites, showing increased percentage of weight loss. The additional peak found for ACT-FPC and BCT-FPC from the FTIR analysis demonstrates that the acetic anhydride and benzoyl chloride have interacted chemically with the SGF. The increased intensity of the XRD peak suggests an 

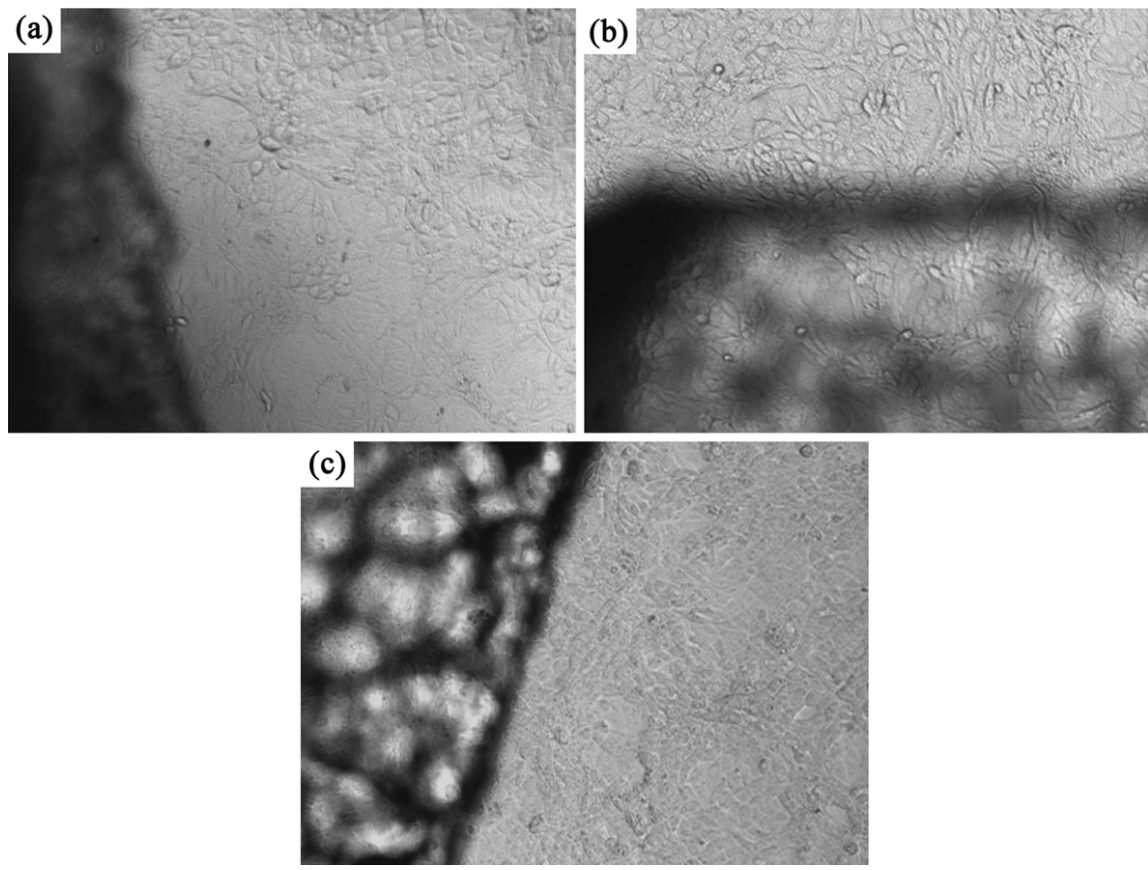

Figure 13. Images of cytotoxic effect of (a) 5ALT-FPC, (b) 5ACT-FPC, and (c) 5BCT-FPC.

Table 3. Cytotoxic effect observation of 5ALT-FPC, 5ACT-FPC and 5BCT-FPC.

\begin{tabular}{ccc}
\hline Sample ID & Survival of cells (Vero) & Remarks/Results \\
\hline Solvent $(-)$ & $100 \%$ & \\
5 ALT-FPC & $>95 \%$ & No cytotoxicity was observed on \\
5 ACT-FPC & $>95 \%$ & Vero cell (non-cancer cell) line. \\
5 BCT-FPC & $>95 \%$ & \\
\hline
\end{tabular}

increase in crystallinity of the composites. The formation of voids within the PLA matrix is minimized by fiber treatment, indicating that after the treatment of SGF with chemicals, the interfacial adhesion between PLA and SGF is improved. The chemical treatment of SGF has increased the compressive strength of the composites. The highest value of mechanical strength and thermal stability are found for BCT-FPC. The composites show no antibacterial activities, confirming degradable by bacteria or other micro organs in environment. The composites also didn't show any cytotoxicity on Vero cell (non-cancer cell) line, so that non-cancer cell will be grown and these are not harmful to use in human body for medical purposes. The composites, prepared by treated SGF can be used by substitute of the non-degradable composite materials.

\section{References}

[1] Mohanty, A.K., Misra, M. and Hinrichsen, G. (2000) Biofibers, Biodegradable Polymers and Biocomposites: An Overview. Macromolecular Materials and Engineering, 276, 1-24.

https://doi.org/10.1002/(SICI)1439-2054(20000301)276:1<1::AID-MAME1>3.0.CO; 
2-W

[2] Shibata, M., Oyamada, S., Kobayashi, S. and Yaginuma, D. (2004) Mechanical Properties and Biodegradability of Green Composites Based on Biodegradable Polyesters and Lyocell Fabric. Journal of Applied Polymer Science, 92, 3857-3863. https://doi.org/10.1002/app.20405

[3] Zini, E., Baiardo, M., Armelao, L. and Scandola, M. (2004) Biodegradable Polyesters Reinforced with Surface-Modified Vegetable Fibers. Macromolecular Bioscience, 4, 286-295. https://doi.org/10.1002/mabi.200300120

[4] Raghavan, D. and Emekalam, A. (2001) Characterization of Starch/Polyethylene and Starch/Polyethylene/Poly(lactic acid) Composites. Polymer Degradation and Stability, 72, 509-517. https://doi.org/10.1016/S0141-3910(01)00054-4

[5] Rosa, D.S., Rodrigues, T., Guedes, C.G. and Calil, M.R. (2003) Effect of Thermal Aging on the Biodegradation of PCL, PHBV and Their Blends with Starch in Soil Compost. Journal of Applied Polymer Science, 89, 3539-3546. https://doi.org/10.1002/app.12537

[6] Lee, S.H. and Ohkita, T. (2003) Mechanical and Thermal Flow Properties of Wood Fiber-Biodegradable Polymers Composites. Journal of Applied Polymer Science, 90, 1900-1905. https://doi.org/10.1002/app.12864

[7] Garlotta, D. (2001) A Literature Review of Poly(lactic acid). Journal of Polymers and the Environment, 9, 63-84. https://doi.org/10.1023/A:1020200822435

[8] Lim, L.-T., Auras, R. and Rubino, M. (2008) Processing Technologies for Poly(lactic acid). Progress in Polymer Science, 33, 820-852.

https://doi.org/10.1016/j.progpolymsci.2008.05.004

[9] Savioli, L.M., Jardini, A. and Maciel, F.R. (2014) Synthesis and Characterizations of Poly(lactic acid) by Ring-Opening Polymerization for Biomedical Applications. Chemical Engineering Transactions, 38, 331-336.

[10] Viswas, M.G., Aristippos, G. and Milford, A.H. (2001) Laboratory Composting of Extruded Poly(lactic acid) Sheets. Bioresource Technology, 76, 57-61. https://doi.org/10.1016/S0960-8524(00)00077-8

[11] Wang, H., Sun, X.Z. and Seib, P. (2001) Strengthening Blends of Poly(lactic acid) and Starch with Methylenediphenyl Diisocyanate. Journal of Applied Polymer Science, 82, 1761-1767. https://doi.org/10.1002/app.2018

[12] Shibata, M., Takachiyo, K.-I., Ozawa, K., Yosomiya, R. and Takeishi, H. (2002) Biodegradable Polyester Composites Reinforced with Short Abaca Fiber. Journal of Applied Polymer Science, 85, 129-138. https://doi.org/10.1002/app.10665

[13] Ghali, L., Msahli, S., Zidi, M. and Sakli, F. (2011) Effects of Fiber Weight Ratio, Structure and Fiber Modification onto Flexural Properties of Luffa-Polyester Composites. Advances in Materials Physics and Chemistry, 1, 78-85. https://doi.org/10.4236/ampc.2011.13013

[14] Saw, S.K., Purwar, R., Nandy, S., Ghose, J. and Sarkhel, G. (2013) Fabrication, Characterization and Evaluation of Luffa cylindrica Fiber Reinforced Epoxy Composites. BioResources, 8, 4805-4826. https://doi.org/10.15376/biores.8.4.4805-4826

[15] Boynard, C.A. and D'Almeida, J.R.M. (1999) Water Absorption by Sponge Gourd (Luffa cylindrica)-Polyester Composite Materials. Journal of Material Science Letters, 18, 1789-1791. https://doi.org/10.1023/A:1006643630959

[16] Panneerdhass, P., Gnanavelbabu, A. and Rajkumar, K. (2014) Mechanical Properties of Luffa Fiber and Ground Nut Reinforced Epoxy Polymer Hybred Composites. Procedia Engineering, 97, 2042-2051. https://doi.org/10.1016/j.proeng.2014.12.447 
[17] Seki, Y., Sever, K., Erden, S., Sarikanat, M., Neser, G. and Ozes, C. (2011) Characterization of Luffa cylindrica Fibers and the Effect of Water Aging on the Mechanical Properties of Its Composite with Polyester. Journal of Applied Polymer Science, 123, 2330-2337. https://doi.org/10.1002/app.34744

[18] Patel, V.K. and Dhanola, A. (2016) Influence of $\mathrm{CaCO}_{3}, \mathrm{Al}_{2} \mathrm{O}_{3}$, and $\mathrm{TiO}_{2}$ Microfillers on Physico-Mechanical Properties of Luffa cylindrica/Polyester Composites. Engineering Science and Technology, 19, 676-683.

https://doi.org/10.1016/j.jestch.2015.10.005

[19] Akgul, M., Korkut, S., Camhbel, O. and Ayata, U. (2013) Some Chemical Properties of Luffa and Its Suitability for Medium Density Fiberboard (MDF) Production. BioResources, 8, 1709-1717. https://doi.org/10.15376/biores.8.2.1709-1717

[20] Mohanta, N. and Acharya, S.K. (2015) Mechanical and Tribological Performance of Luffa cylindrica Fibre-Reinforced Epoxy Composite. BioResources, 10, 8364-8377. https://doi.org/10.15376/biores.10.4.8364-8377

[21] Mani, P., Dellibabu, G.V., Anilbasha, K. and Anbukarsi, K. (2014) Tensile and Flexural Properties of Luffa Fiber Reinforced Composite Material. International Journal of Engineering Research and Technology, 3, 1882-1885.

[22] Al-Mobarak, T., Mina, M.F., Gafur, M.A., Ahmed, A.N. and Dhar, S.A. (2018) Effect of Chemical Modifications on Surface Morphological, Structural, Mechanical, and Thermal Properties of Sponge-Gourd Natural Fiber. Fibers and Polymers, 19, 31-40. https://doi.org/10.1007/s12221-018-7199-3

[23] Avella, M., Bogoeva-Gaceva, G., Buzarovska, A., Errico, M.E., Gentile, G. and Grozdanov, A. (2008) Poly(lactic acid)-Based Biocomposites Reinforced with Kenaf Fibers. Journal of Applied Polymer Science, 108, 3542-3551. https://doi.org/10.1002/app.28004

[24] Ma, H. and Joo, C.W. (2010) Structure and Mechanical Properties of Jute-Polylactic Acid Biodegradable Composites. Journal of Composite Materials, 45, 1451-1460. https://doi.org/10.1177/0021998310382316

[25] Alam, A.K.M.M., Beg, M.D.H., Mina, M.F., Mamun, A.A. and Bledzki, A.K. (2015) Degradation and Stability of Green Composites Fabricated from Oil Palm Empty Fruit Bunch Fiber and Polylactic Acid: Effect of Fiber Length. Journal of Composite Materials, 49, 3103-3114. https://doi.org/10.1177/0021998314560219

[26] Lee, S.H. and Wang, S. (2006) Biodegradable Polymers/Bamboo Fiber Biocomposite with Bio-Based Coupling Agent. Composites: Part- $A$, 37, 80-91. https://doi.org/10.1016/j.compositesa.2005.04.015

[27] Islam, M.S., Pickering, K.L. and Foreman, N. (2010) Influence of Accelerated Ageing on the Physico-Mechanical Properties of Alkali-Treated Industrial Hemp Fiber Reinforced Poly(lactic acid) (PLA) Composites. Polymer Degradation and Stability, 95, 59-65. https://doi.org/10.1016/j.polymdegradstab.2009.10.010

[28] Aydin, M., Tozlu, H., Kemaloglu, S., Aytac, A. and Ozkoc, G. (2011) Effects of Alkali Treatment on the Properties of Short Flax Fiber-Poly(lactic acid) Eco-Composites. Journal of Polymers and the Environment, 19, 11-17. https://doi.org/10.1007/s10924-010-0233-9

[29] Majhi, S.K., Nayak, S.K., Mohanty, S. and Unnikrishnan, L. (2010) Mechanical and Fracture Behavior of Banana Fiber Reinforced Polylactic Acid Biocomposites. International Journal of Plastic Technology, 14, 57-75. https://doi.org/10.1007/s12588-010-0010-6

[30] Vimala, K., Yallapu, M.M., Varaprasad, K., Redd, N.N., Ravindra, S., Naidu, N.S. and Raju, K.M. (2011) Fabrication of Curcumin Encapsulated Chitosan-PVA Silver 
Nanocomposite Films for Improved Antimicrobial Activity. Journal of Biomaterials and Nanobiotechnology, 2, 55-64. https://doi.org/10.4236/jbnb.2011.21008

[31] Al-Mobarak, T., Mina, M.F. and Gafur, M.A. (2013) Material Properties of Acetylated Jute-Mat Composites. Journal of Scientific Research, 5, 13-23. http://doi.org/10.3329/jsr.v5i1.11798

[32] Tham, W.L., Ishak, Z.A. and Chow, W.S. (2014) Water Absorption and Hygrothermal Aging Behaviors of SEBS-g-MAH Toughened Poly(lactic acid)/Halloysite Nanocomposites. Polymer Plastics Technology and Engineering, 53, 472-480. https://doi.org/10.1080/03602559.2013.845208

[33] Marega, C., Marigo, A., DiNoto, V. and Zannetti, R. (1992) Structure and Crystallization Kinetics of Poly(L-lactic acid). Die Makromolekulare Chemie, 193, 1599-1606. https://doi.org/10.1002/macp.1992.021930704

[34] Miloud, B. (2005) Permeability and Porosity Characteristics of Steel Fiber Reinforced Concrete. Asian Journal of Civil Engineering, 6, 317-330.

[35] Sahmaran, M. and Yaman, I.O. (2007) Hybrid Fiber Reinforced Self-Compacting Concrete with a High-Volume Coarse Fly Ash. Construction and Building Materials, 21, 150-156. https://doi.org/10.1016/j.conbuildmat.2005.06.032

[36] Felekoglu, B., Turkel, S. and Altuntas, Y. (2007) Effects of Steel Fiber Reinforcement on Surface Wear Resistance of Self-Compacting Repair Mortars. Cement Concrete Composites, 29, 391-396. https://doi.org/10.1016/j.cemconcomp.2006.12.010

[37] Mina, M.F., Seema, S., Matin, R., Rahman, M.J., Sarker, R.B., Gafur, M.A. and Bhuiyan, M.A.H. (2009) Improved Performance of Isotactic Polypropylene/Titanium Dioxide Composites: Effect of Processing Conditions and Filler Content. Polymer Degradation and Stability, 94, 183-188. https://doi.org/10.1016/j.polymdegradstab.2008.11.006

[38] Lever, S.D. and Papadaki, M. (2004) Study of Condition-Dependent Decomposition Reactions: The Thermal Behavior and Decomposition of 2-Nitrobenzoyl Chloride, Part-I. Journal of Hazardous Materials, 115, 91-100. https://doi.org/10.1016/j.jhazmat.2004.05.026

[39] Bledzki, A.K. and Gassan, J. (1999) Composites Reinforced with Cellulose Based Fibers. Progress in Polymer Science, 24, 221-274. https://doi.org/10.1016/S0079-6700(98)00018-5 